\title{
Technique of precise order preference for multiple risk assessment in occupational health and safety: Industrial case study
}

DOI : $10.36909 /$ jer.14153

\author{
Nazli Gulum Mutlu*, Serkan Altuntas ${ }^{* *}$ \\ *Department of Occupational Health and Safety, Faculty of Health Sciences, Bingol University, \\ Bingol, 12000, Turkey. \\ *** Department of Industrial Engineering, Faculty of Mechanical Engineering, Yildiz Technical \\ University, Istanbul, 34349, Turkey. \\ *Email: ngmutlu@bingol.edu.tr; Corresponding Author.
}

\begin{abstract}
Risk assessment in manufacturing, construction or service systems are very important tools for ensuring occupational health and safety. Many risk assessment approaches have been proposed in the literature, each with its advantages and disadvantages. In the literature, the authors attempt to develop methods to overcome some of these disadvantages. Different risk priority orders can be obtained for the same failure types with the developed and traditional approaches, and the results may be inconsistent. Hence, different methods produce inconsistent risk ranking outcomes for the same risk assessment problem. This causes confusion for decision-makers when deciding the most-risky failure modes. In this study, the application of the Technique of Precise Order Preference (TPOP) for risk assessment in the field of occupational health and safety (OHS) is conducted to fill the gap in the literature concerning the problem in question and to solve the ranking inconsistency problem related to occupational health and safety. The results of this study show that the advantages obtained from different methods can be combined and a favorable risk priority order can be acquired for decisionmakers.
\end{abstract}


Key words: Risk assessment; risk ranking; occupational health and safety; technique of precise order preference.

\section{INTRODUCTION}

One of the most critical objectives of occupational health and safety is the identification, analysis and evaluation of risks or hazards (Saracino et al., 2015; OHS Risk Assessment Regulation, 2012; 89/391/EEC, 1989; ISO 31000, 2018). Hazard management is one of the research area of industrial information integration (Chen, 2016). Risk assessment and management was established as a scientific field not more than 30-40 years old and therefore, it is a young field (Aven, 2016). There is a strong correlation between the success of risk analysis, the experience of decision-makers as occupational safety professionals, and compliance with relevant standards and legal regulations. Occupational safety professionals are responsible for identifying hazards in the workplace, educating employees about these hazards, and guiding employees to do their jobs correctly (Friend \& Kohn, 2007).

The main purpose of risk assessment is to understand risks and to prevent occupational accidents, illness, injury, disability and death through an in-depth systematic analysis of hazards (AlSabah \& Refaat, 2019; Akdağ et al., 2016). Risk analysis and risk prioritization topics within the framework of risk assessment have become important areas of study from a broad perspective. Studies within the context of the manufacturing industry have dealt with the identification of risks that cause production downtime, analysis of machine-equipment maintenance risks (Boye \& Samuel, 2020; Antosz \& Ratnayake, 2019; Alencar \& de Almeida, 2015; Vaurio, 2011; Sharma \& Sharma, 2010), assessment of risks that affect product quality negatively, identification of risks that enterprises face owing to the gap between demand and supply, and the analysis of the risks of products being out of stock during the assembly process (Fakhrzad et al., 2021; Manzini \& Urgo, 2018; Ocampo et al., 2016; Bettayeb et al., 2014; 
Pariyani et al., 2012; Segismundo \& Augusto Cauchick Miguel, 2008). Traditional risk assessment methods are insufficient for accurate risk evaluation due to equal priority risk ranking results and the calculation of risk indexes of equal weight (Emovon and Mgbemena, 2019; Bian et al., 2015; Lv and Liang, 2014). Analyzing risks and taking precautions based on the most-appropriate risk ranking have become important fields of research for both improving occupational health and safety and enhancing production and service processes. Many new approaches have been proposed in the literature to improve the shortcomings of traditional risk assessment methods and to achieve a reliable risk priority order. Inconsistent risk rankings are obtained using these developed methods for similar risk prioritization problems (Exp: Sachdeva et al., 2009; Kutlu and Ekmekçioğlu, 2012; Song et al., 2013). Which of these developed methods should the occupational safety professional choose? There is a gap in the literature on this topic.

In this study, the advantages of the technique of precise order preference (TPOP) are utilized to overcome this problem. It should be noted that the novelty of this work is using the TPOP to prioritize failure modes in the risk analysis context. The TPOP eliminates inappropriate weights distribution and overcomes the rank reversal of the traditional approaches (Bairagi et al., 2015).

A case study in manufacturing systems is conducted to demonstrate the application of the TPOP in practice. This study addresses ranking inconsistency problem in the field of occupational health and safety and provides a solution for the problem.

The remaining parts of this study are organized as follows. Literature review is given in Section 2. The TPOP is introduced in Section 3. Applications of the case study to manufacturing systems is shown in Section 4. Results and discussion are given in Section 5. Finally, conclusions are provided in Section 5. 


\section{METHODOLOGY}

Bairagi et al. (2015) suggested the use of the TPOP for rankings obtained from traditional approaches. They noted that, although the selection problem was the same, different rankings were obtained with different the Multiple Criteria Decision Making (MCDM) approaches and that there was uncertainty for decision-makers because of the lack of consensus as to which MCDM ranking was best. They proposed the TPOP to overcome this problem. Various methods have been developed for use in sequencing/prioritization problems. Decision-makers obtain different sorting orders with different methods for the same sorting problem. Each method provides different advantages in solving a problem, and because the steps used in the execution of each method are different, multiple sequencing is achieved. The main problem here is the inconsistencies between rankings and determining which ranking is more accurate.

In this study, the TPOP was used because of the different order of priorities obtained as a result of the different approaches employed to prioritize risks in the occupational health and safety field. In TPOP prioritization problems, a single order is attained by using data belonging to different rankings obtained using more than one method in an integrated manner. Thus, the advantages provided by sequences obtained using multiple methods are converted into a single sequence without loss of information. The following 11 steps describe the implementation of the TPOP (Bairagi et al., 2015).

Step 1: If it is necessary to prioritize alternatives based on predefined criteria, decision-makers evaluate each alternative using various methods in relation to the predefined criteria and assign a final selection value (Dey et al., 2016). Multiple MCDM methods produce different final selection values for the same alternatives. (Bairagi et al., 2015; Zolfaghari and Mousavi, 2021; Ekinci and Can, 2021). The final selection values obtained using the MCDM approaches and the decision matrix are formed for the alternatives. Here, $\mathrm{i}=1,2, \ldots \mathrm{m}$ and $\mathrm{j}=1,2, \ldots$ t. $A_{i}$ shows 
the $\mathrm{i}$-th alternative, $f_{i j}, A_{i}$ represents the final selection values obtained using the $\mathrm{j}$-th MCDM approach.

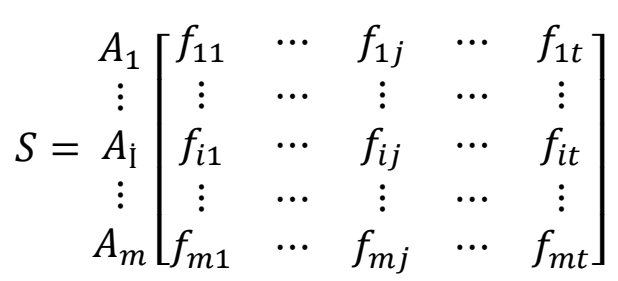

Step 2: The final selection values obtained using different MCDM methods vary over a very wide range. Proximity coefficients take values in the range $0-1$, while the degree of use can take values in the range $0-100$. However, the negative selection values can be calculated using methods such as MOORA and ELECTRE (Bairagi et al., 2015). To evaluate these values together, we calculate the normalized value of the final selection values obtained using $\mathrm{j}$ different MCDM methods $\tau_{i j}$ and the absolute value of the final selection value of the alternative i obtained using the $\mathrm{j}$-th approach, where $\left|f_{i j}\right|$ is expressed with $\tau_{i j}$ and $0 \leq \tau_{i j} \leq 1$. Equation (2) is used for normalization.

$$
\tau_{i j}=\frac{\left|f_{i j}\right|}{\sum_{i=1}^{m}\left|f_{i j}\right|}
$$

Step 3: For each MCDM approach, the entropy values are calculated using normalized values of the final selection values. Equation (3) is used to calculate the entropy value.

$$
e_{j}=\frac{1}{\ln m} \sum_{i=1}^{m}\left|\tau_{i j} * \ln \tau_{i j}\right|
$$

Step 4: Equation (4) is used to calculate the apparent weight value of the $\mathrm{j}$-th approach $s_{j}$.

$$
s_{j}=\frac{1-e_{j}}{\sum_{j=1}^{t}\left(1-e_{j}\right)}
$$

Bairagi et al. (2015) proposed an advanced entropy weighting method to increase the effect of features with negligible weights and to calculate the objective weights of the final selection values. In steps 5-7, the improved version of the entropy method was used. 
Step 5: Here, $0 \leq s_{j} \leq 1$, where $s_{j}$ takes the minimum and maximum values of 0 and 1 , respectively. The ratio of the maximum $s_{j}$ value to the minimum $s_{j}$ value can be infinite, and when qualities are compared, some may be insignificant. This is an undesirable situation, and to overcome this problem by reducing the ratio of $\max \left(s_{j}^{\prime}\right)$ to $\min \left(s_{j}^{\prime}\right), s_{j}$ is utilized, and $s_{j}^{\prime}$ value is calculated using Equation (5) (Bairagi et al., 2015).

Here, the minimum value of $s_{j}^{\prime}=1$, at $s_{j}=0$,

the maximum value of $s_{j}^{\prime}=2$, at $s_{j}=1$.

In this way, $1 \leq s_{j}^{\prime} \leq 2$, and the maximum $s_{j}^{\prime \prime}$ s minimum $s_{j}^{\prime \prime} e$ ratio is $2 / 1=2$. This value is considered to be an acceptable limit value (Bairagi et al.,2015).

$$
s_{j}^{\prime}=\left(1+\sqrt{s_{j}}\right)
$$

Step 6: The $s_{j}^{\prime}$ values calculated for each MCDM method are summed, and $S_{j}^{\prime}$ is obtained (see Equation (6)). Here, $1 \leq s_{j}^{\prime} \leq 2$ and is limited to the range $t \leq S_{j}^{\prime} \leq 2 t . s_{j}^{\prime}$ and $S_{j}^{\prime}$ are real numbers and are dimensionless. The number of traditional selection methods is $\mathrm{t}$, and $\mathrm{t} \geq 2$.

$$
S_{j}^{\prime}=\sum_{j=1}^{t} s_{j}^{\prime}=\sum_{j=1}^{t}\left(1+\sqrt{s_{j}}\right)
$$

Step 7: The absolute weight of the final selection value determined using the $\mathrm{j}$-th approach $w_{j}$ is obtained by the proportioning of $s_{j}^{\prime}$ to $S_{j}^{\prime}$. Equation (7) calculates $w_{j}$.

$$
w_{j}=\frac{s_{j}^{\prime}}{S_{j}^{\prime}}=\frac{1+\sqrt{s_{j}}}{\sum_{j=1}^{t}\left(1+\sqrt{s_{j}}\right)}
$$

Step 8: The final selection values are normalized for the evaluation of alternatives. Equation (8) is used for normalizing. Here, $g_{i j}$ shows the normalized values of $f_{i j}$, and $0 \leq g_{i j} \leq 1$. $\left(f_{j}\right)_{\max }$ represents the maximum selection value determined using the $\mathrm{j}$-th approach, whereas $\left(f_{j}\right)_{\min }$ represents the minimum selection value determined using the $\mathrm{j}$-th approach. Further, the formulae in $f_{i j} \in H$ when $f_{i j}$ has its maximum value and in $f_{i j} \in L$ when $f_{i j}$ has its 
minimum value are shown in Equation (8). The lowest $g_{i j}$ indicates that the best alternative is closest to the optimum solution.

$$
g_{i j}= \begin{cases}\frac{\left(f_{j}\right)_{\max }-f_{i j}}{\left(f_{j}\right)_{\max }-\left(f_{j}\right)_{\min }}, & f_{i j} \in H \\ \frac{f_{i j}-\left(f_{j}\right)_{\min }}{\left(f_{j}\right)_{\max }-\left(f_{j}\right)_{\min }}, & f_{i j} \in L\end{cases}
$$

Step 9: The exponent of the final selection values of the weighted and normalized final selection values obtained using the $\mathrm{j}$-th approach for the $\mathrm{i}$-th alternative is calculated by $h_{i j}$ in Equation (9).

$$
h_{i j}=\exp \left(w_{j}+g_{i j}\right)
$$

Step 10: The precise selection index (PSI) for each alternative $\mathrm{PSI}_{i}$ is calculated using Equation (10).

$$
\mathrm{PSI}_{i}=\sum_{j=1}^{t} h_{i j}=\sum_{j=1}^{t} \exp \left(w_{j}+g_{i j}\right)
$$

Step 11: The alternatives are sorted in ascending order of PSI values. The grade of the alternative with the smallest PSI value is determined to be 1 , and the next alternative grade is determined to be 2 . In this way, the most recent alternative with the highest PSI value is considered to be the worst alternative.

\section{Application of the TPOP}

In this study, the applicability of the TPOP for the risk analysis and evaluation process is discussed in detail. Final risk values obtained with different risk assessment approaches were used for two different cases encountered in production systems. The problem and solution approach flow discussed is shown in Figure 2. In the following sections, the application of the TPOP and the results obtained are discussed considering a case study. 


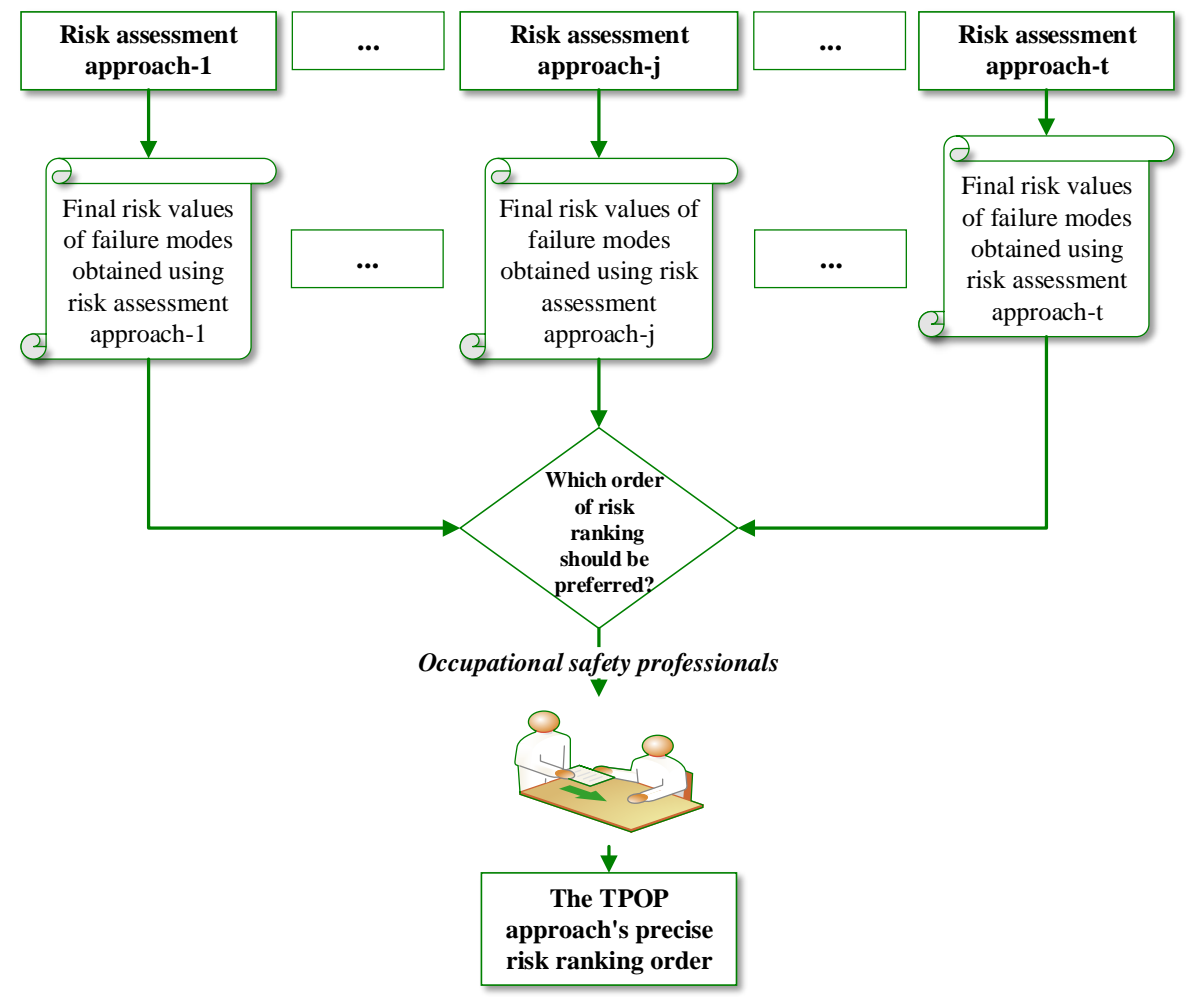

Figure 2 The motivation to study

\section{Case study}

Eight failure modes defined by Song et al. (2013) for reheat valve system in nuclear steam turbine were considered in Case study. Song et al. (2013) mechanical failure types that may cause abnormal operation of the nuclear reheating valve system is determined to ensure safety and reliability in the system. Failure modes and severity (S), occurrence (O), and detectability (D) values for nuclear reheating valve system are given in Table 1. For example, the risk priority number $R P N=9 * 4 * 7=252$ for $F M_{1}$ is calculated in the same manner as risk priorities for other failure modes. One risk ranking assignment is made for the largest RPN (see Table 2). The fuzzy TOPSIS-based weighted FMEA approach for failure modes (Song et al., 2013), TOPSIS approach (Sachdeva et al., 2000), fuzzy TOPSIS-fuzzy AHP-fuzzy FMEA approach (Kutlu \& Ekmekçioğlu, 2012), and the information concerning the final risk values obtained using classical FMEA approaches are listed in Table 2 . Here $\mathrm{i}=1,2, \ldots 20$, and $\mathrm{j}=1,2,3,4$. $R S_{i j}$ and $F M_{i}$ represent the final risk scores obtained using the $\mathrm{j}$-th risk assessment approach. 
Table 1 Failure modes and severity $(\mathrm{S})$, occurrence $(\mathrm{O})$, and detectability $(\mathrm{D})$ values for nuclear reheating valve system (Kutlu \& Ekmekçioğlu, 2012)

\begin{tabular}{llccc}
\hline $\boldsymbol{F} \boldsymbol{M}_{\boldsymbol{i}}$ & Failure Mode & S & O & D \\
\hline$F M_{1}$ & Valve' closing time is too long or no action & 9 & 4 & 7 \\
$F M_{2}$ & Valve cannot be closed tightly & 3 & 4 & 4 \\
$F M_{3}$ & Large leak of valve shaft & 4 & 6 & 4 \\
$F M_{4}$ & Valve fluctuations & 6 & 4 & 4 \\
$F M_{5}$ & Valve jam when opening and closing & 9 & 4 & 4 \\
$F M_{6}$ & Valve shaft fructure & 10 & 4 & 3 \\
$F M_{7}$ & Manufaction of valve shaft support bearing & 8 & 7 & 2 \\
$F M_{8}$ & Excessive noise or abnormal noise of valve system & 6 & 6 & 5 \\
\hline
\end{tabular}

Step 1: For each failure mode $F M_{i}$, the final risk scores for each risk assessment approach $R S_{i j}$ were used. The decision matrix $S^{1}$ was formed by using Equation (1). Here $\mathrm{i}=1,2, \ldots 20$, and $\mathrm{j}=1,2,3,4 . R S_{i j}$, and $F M_{i}$ represent the final risk scores obtained using the $\mathrm{j}$-th risk assessment approach.

Table 2 Final risk values obtained using four failure mode approaches (Song et al., 2013)

\begin{tabular}{|c|c|c|c|c|c|c|c|c|}
\hline \multirow[t]{2}{*}{$F M_{i}$} & \multicolumn{2}{|c|}{$\begin{array}{l}\text { Sachdeva et al. } \\
\text { (2009) }\end{array}$} & \multicolumn{2}{|c|}{$\begin{array}{c}\text { Kutlu and } \\
\text { Ekmekçioğlu } \\
\text { (2012) }\end{array}$} & \multicolumn{2}{|c|}{ Song et al. (2013) } & \multicolumn{2}{|c|}{$\begin{array}{c}\text { Conventional } \\
\text { FMEA }\end{array}$} \\
\hline & $\mathrm{CC}_{\mathrm{i}}{ }^{*}$ & Ranking & $\mathrm{CC}_{\mathrm{i}}$ & Ranking & $\mathrm{CC}_{\mathrm{i}}$ & Ranking & $\mathbf{R P N}^{* * *}$ & Ranking \\
\hline$F M_{1}$ & 0.794 & 1 & 0.253 & 1 & 0.2379 & 1 & 252 & 1 \\
\hline$F M_{2}$ & 0.210 & 8 & 0.124 & 8 & 0.1324 & 8 & 48 & 7 \\
\hline$F M_{3}$ & 0.300 & 7 & 0.159 & 6 & 0.1721 & 6 & 96 & 6 \\
\hline$F M_{4}$ & 0.438 & 6 & 0.155 & 7 & 0.1465 & 7 & 96 & 6 \\
\hline$F M_{5}$ & 0.650 & 2 & 0.202 & 2 & 0.1941 & 3 & 144 & 3 \\
\hline$F M_{6}$ & 0.623 & 3 & 0.194 & 4 & 0.1770 & 5 & 120 & 4 \\
\hline$F M_{7}$ & 0.534 & 5 & 0.197 & 3 & 0.1955 & 2 & 112 & 5 \\
\hline$F M_{8}$ & 0.544 & 4 & 0.189 & 5 & 0.1991 & 4 & 180 & 2 \\
\hline Total & 4.093 & & 1.473 & & 1.4546 & & 1,048 & \\
\hline
\end{tabular}

${ }^{*} \mathrm{CC}$ : Closeness coefficient, ${ }^{* *} \mathrm{RPN}$ : Risk priority number. 


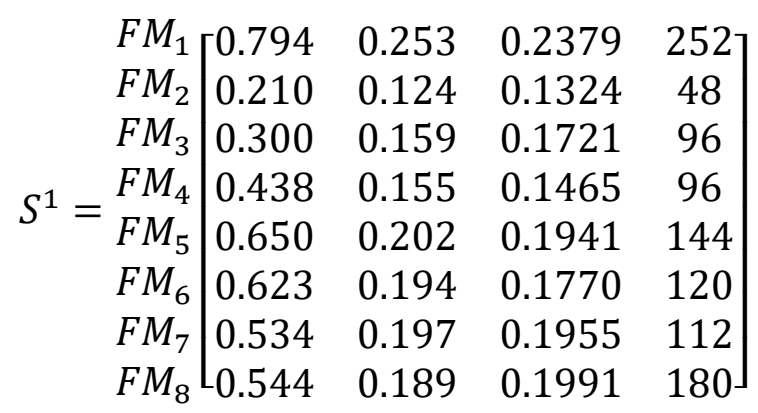

Step 2: The risk scores obtained with different risk assessment approaches varied between 0.124 and 252. These values were normalized using Equation (2), to evaluate the final risk scores obtained using each risk assessment method for failure modes (see Table 3). For example, in this case $\tau_{11}=0.794 / 4.093=0.1940$ is computed. Similarly, normalized values were computed for the other final risk scores.

Table 3 Normalized risk scores

\begin{tabular}{ccccccccc}
\hline $\boldsymbol{F} M_{\boldsymbol{i}}$ & $\begin{array}{c}\text { Sachdeva } \text { et al. } \\
(\mathbf{2 0 0 9 )}\end{array}$ & $\begin{array}{c}\text { Kutlu and } \\
\text { Ekmekçioğlu } \\
(\mathbf{2 0 1 2})\end{array}$ & $\begin{array}{c}\text { Song } \boldsymbol{e t} \text { al. } \\
\mathbf{( 2 0 1 3 )}\end{array}$ & \multicolumn{2}{c}{$\begin{array}{c}\text { Conventional } \\
\text { FMEA }\end{array}$} \\
\hline$F M_{1}$ & $\tau_{11}$ & 0.1940 & $\tau_{12}$ & 0.1718 & $\tau_{13}$ & 0.1635 & $\tau_{14}$ & 0.2405 \\
$F M_{2}$ & $\tau_{21}$ & 0.0513 & $\tau_{22}$ & 0.0842 & $\tau_{23}$ & 0.0910 & $\tau_{24}$ & 0.0458 \\
$F M_{3}$ & $\tau_{31}$ & 0.0733 & $\tau_{32}$ & 0.1079 & $\tau_{33}$ & 0.1183 & $\tau_{34}$ & 0.0916 \\
$F M_{4}$ & $\tau_{41}$ & 0.1070 & $\tau_{42}$ & 0.1052 & $\tau_{43}$ & 0.1007 & $\tau_{44}$ & 0.0916 \\
$F M_{5}$ & $\tau_{51}$ & 0.1588 & $\tau_{52}$ & 0.1371 & $\tau_{53}$ & 0.1334 & $\tau_{54}$ & 0.1374 \\
$F M_{6}$ & $\tau_{61}$ & 0.1522 & $\tau_{62}$ & 0.1317 & $\tau_{63}$ & 0.1217 & $\tau_{64}$ & 0.1145 \\
$F M_{7}$ & $\tau_{71}$ & 0.1305 & $\tau_{72}$ & 0.1337 & $\tau_{73}$ & 0.1344 & $\tau_{74}$ & 0.1069 \\
$F M_{8}$ & $\tau_{81}$ & 0.1329 & $\tau_{82}$ & 0.1283 & $\tau_{83}$ & 0.1369 & $\tau_{84}$ & 0.1718 \\
\hline Total & & $\mathbf{1 . 0 0 0}$ & & $\mathbf{1 . 0 0 0}$ & & $\mathbf{1 . 0 0 0}$ & & $\mathbf{1 . 0 0 0}$ \\
\hline
\end{tabular}

Steps 3-7: In the previous step, the final selection values, whose ranges vary greatly for each risk assessment approach and failure modes, were converted into normalized final risk scores. For the approaches used to prioritize failure modes in case, $e_{j}$ of Equation (3), $s_{j}$ of Equation (4), $s_{j}^{\prime}$ of Equation (5), $S_{j}^{\prime}$ of Equation (6), and $w_{j}$ were obtained by using Equation (7) .

For Sachdeva et al. (2009), $\quad \sum_{i=1}^{8}\left|\tau_{i j} * \ln \tau_{i j}\right|=|0,1940 * \ln 0,1940|+\mid 0,0513 *$ $\ln 0,0513|+| 0,0733 * \ln 0,0733|+| 0,1070 * \ln 0,1070|+| 0,1588 * \ln 0,1588 \mid+$ 
$|0,1522 * \ln 0,1522|+|0,1305 * \ln 0,1305|+|0,1329 * \ln 0,1329|=2,0139$ and $e_{1}=$ $\frac{1}{\ln m} \sum_{i=1}^{m}\left|\tau_{i j} * \ln \tau_{i j}\right|=\frac{2,0139}{\ln 8}=0,9685$

In addition, $s_{1}=\frac{1-e_{j}}{\sum_{j=1}^{t}\left(1-e_{j}\right)}=\frac{1-0,9685}{0,0935}=0,3370$, and $s_{1}^{\prime}=\left(1+\sqrt{s_{1}}\right)=(1+\sqrt{0,3370})=$ 1,5805. Finally, $w_{1}=\frac{s_{1}^{\prime}}{s_{j}^{\prime}}=\frac{1+\sqrt{s_{j}}}{\sum_{j=1}^{t}\left(1+\sqrt{s_{j}}\right)}=\frac{1,5805}{5,8678}=0,2694$.

Table 4 Risk assessment approach values $\mathrm{e}_{\mathrm{j}}, \mathrm{s}_{\mathrm{j}}, \mathrm{s}_{\mathrm{j}}^{\prime}, \mathrm{S}_{\mathrm{j}}^{\prime}$, and $\mathrm{w}_{\mathrm{j}}$

\begin{tabular}{lccccc}
\hline Risk assessment approach & $\mathbf{e}_{\mathbf{j}}$ & $\mathbf{s}_{\mathbf{j}}$ & $\mathbf{s}_{\mathbf{j}}^{\prime}$ & $\mathbf{S}_{\mathbf{j}}^{\prime}$ & $\mathbf{w}_{\mathbf{j}}$ \\
\hline Sachdeva et al. (2009) & $\mathbf{0 . 9 6 8 5}$ & $\mathbf{0 . 3 3 7 0}$ & $\mathbf{1 . 5 8 0 5}$ & & $\mathbf{0 . 2 6 9 4}$ \\
Kutlu and Ekmekçioğlu (2012) & 0.9907 & 0.0994 & 1.3152 & & 0.2241 \\
Song et al. (2013) & 0.9931 & 0.0743 & 1.2725 & & 0.2169 \\
Conventional FMEA & 0.9542 & 0.4893 & 1.6995 & & 0.2896 \\
\hline
\end{tabular}

Step 8: The final risk scores calculated for each failure mode with each risk assessment method were normalized using Equation (8). Following this procedure, the final risk scores obtained with each risk assessment method were converted to a 0-1 scale (see Table 5). For Sachdeva et al. (2009), $\left(f_{1}\right)_{\max }=0,7940$ ve $\left(f_{1}\right)_{\min }=0,2100$ and $g_{11}=\frac{0,7940-0,7940}{0,7940-0,2100}=0,000$, (see Table 5).

Table 5 Final risk scores obtained with each risk assessment method for each failure mode $\mathrm{g}_{\mathrm{ij}}$

\begin{tabular}{ccccccccc}
\hline $\boldsymbol{F} M_{\boldsymbol{i}}$ & $\begin{array}{c}\text { Sachdeva } \boldsymbol{e t} \boldsymbol{a l} \text {. } \\
\mathbf{( 2 0 0 9 )}\end{array}$ & $\begin{array}{c}\text { Kutlu and } \\
\text { Ekmekçioğlu } \\
\mathbf{( 2 0 1 2 )}\end{array}$ & $\begin{array}{c}\text { Song } \boldsymbol{e t} \text { al. } \\
\mathbf{( 2 0 1 3 )}\end{array}$ & \multicolumn{2}{c}{$\begin{array}{c}\text { Conventional } \\
\text { FMEA }\end{array}$} \\
\hline$F M_{1}$ & $g_{11}$ & 0.0000 & $g_{12}$ & 0.0000 & $g_{13}$ & 0.0000 & $g_{14}$ & 0.0000 \\
$F M_{2}$ & $g_{21}$ & 1.0000 & $g_{22}$ & 1.0000 & $g_{23}$ & 1.0000 & $g_{24}$ & 1.0000 \\
$F M_{3}$ & $g_{31}$ & 0.8459 & $g_{32}$ & 0.7287 & $g_{33}$ & 0.6237 & $g_{34}$ & 0.7647 \\
$F M_{4}$ & $g_{41}$ & 0.6096 & $g_{42}$ & 0.7597 & $g_{43}$ & 0.8664 & $g_{44}$ & 0.7647 \\
$F M_{5}$ & $g_{51}$ & 0.2466 & $g_{52}$ & 0.3953 & $g_{53}$ & 0.4152 & $g_{54}$ & 0.5294 \\
$F M_{6}$ & $g_{61}$ & 0.2928 & $g_{62}$ & 0.4574 & $g_{63}$ & 0.5773 & $g_{64}$ & 0.6471 \\
$F M_{7}$ & $g_{71}$ & 0.4452 & $g_{72}$ & 0.4341 & $g_{73}$ & 0.4019 & $g_{74}$ & 0.6863 \\
$F M_{8}$ & $g_{81}$ & 0.4281 & $g_{82}$ & 0.4961 & $g_{83}$ & 0.3677 & $g_{84}$ & 0.3529 \\
\hline
\end{tabular}


Step 9: The values of the final risk scores obtained with each risk assessment method for each failure mode $h_{i j}$ were calculated using Equation (9).

For Sachdeva et al. (2009), $h_{11}=\exp \left(w_{1}+g_{11}\right)=\exp (0,2694+0,000)=1,3091$ (see Table 6).

Steps 10-11: For each failure mode, the $\mathrm{PSI}_{i}$ was calculated using Equation (10), and the $\mathrm{PSI}_{i}$ degrees were determined for ranking. For example, $\mathrm{PSI}_{1}=\sum_{j=1}^{4} h_{i j}=1,3091+1,2512+$ $1,2422+1,3359=5,1385$. Table 7 presents the results obtained using other risk analysis and evaluation approaches and the TPOP. The susceptible risk priority order for the eight failure modes is shown in Figure 3.

Table $6 \mathrm{~h}_{\mathrm{ij}}$ values of final risk scores obtained with each risk assessment method for each failure mode in case study

\begin{tabular}{|c|c|c|c|c|c|c|c|c|}
\hline \multirow{2}{*}{$\begin{array}{l}\boldsymbol{F} \boldsymbol{M}_{\boldsymbol{i}} \\
F M_{1}\end{array}$} & \multicolumn{2}{|c|}{$\begin{array}{l}\text { Sachdeva et al. } \\
\qquad(2009)\end{array}$} & \multicolumn{2}{|c|}{$\begin{array}{c}\text { Kutlu and } \\
\text { Ekmekçioğlu } \\
\text { (2012) }\end{array}$} & \multicolumn{2}{|c|}{$\begin{array}{l}\text { Song et al. } \\
\quad(2013)\end{array}$} & \multicolumn{2}{|c|}{$\begin{array}{c}\text { Conventional } \\
\text { FMEA }\end{array}$} \\
\hline & $h_{11}$ & 1.3091 & $h_{12}$ & 1.2512 & $h_{13}$ & 1.2422 & $h_{14}$ & 1.3359 \\
\hline$F M_{2}$ & $h_{21}$ & 3.5586 & $h_{22}$ & 3.4012 & $h_{23}$ & 3.3766 & $h_{24}$ & 3.6315 \\
\hline$F M_{3}$ & $h_{31}$ & 3.0503 & $h_{32}$ & 2.5930 & $h_{33}$ & 2.3177 & $h_{34}$ & 2.8701 \\
\hline$F M_{4}$ & $h_{41}$ & 2.4084 & $h_{42}$ & 2.6747 & $h_{43}$ & 2.9542 & $h_{44}$ & 2.8701 \\
\hline$F M_{5}$ & $h_{51}$ & 1.6752 & $h_{52}$ & 1.8580 & $h_{53}$ & 1.8814 & $h_{54}$ & 2.2683 \\
\hline$F M_{6}$ & $h_{61}$ & 1.7545 & $h_{62}$ & 1.9768 & $h_{63}$ & 2.2125 & $h_{64}$ & 2.5515 \\
\hline$F M_{7}$ & $h_{71}$ & 2.0433 & $h_{72}$ & 1.9314 & $h_{73}$ & 1.8566 & $h_{74}$ & 2.6536 \\
\hline$F M_{8}$ & $h_{81}$ & 2.0086 & $h_{82}$ & 2.0550 & $h_{83}$ & 1.7942 & $h_{84}$ & 1.9014 \\
\hline
\end{tabular}

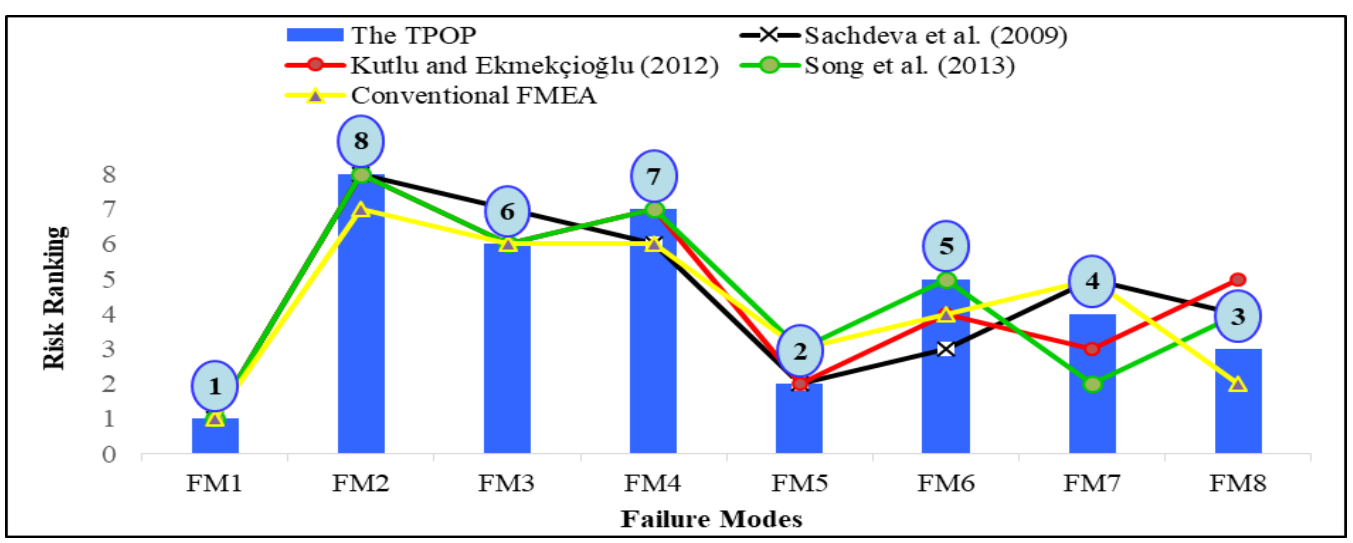


Figure 3 Precise sort order for failure modes in nuclear reheat valve system in case study

Table 7 Degree of risk for each failure mode according to each risk assessment method and degree of risk obtained using TPOP in case study

\begin{tabular}{|c|c|c|c|c|c|c|}
\hline \multirow{2}{*}{$F M_{i}$} & \multirow{2}{*}{$\begin{array}{c}\text { Sachdeva } \\
\text { et al. } \\
(2009) \\
\text { Ranking }\end{array}$} & \multirow{2}{*}{$\begin{array}{c}\begin{array}{c}\text { Kutlu and } \\
\text { Ekmekçioğlu } \\
(2012)\end{array} \\
\text { Ranking }\end{array}$} & \multirow{2}{*}{$\begin{array}{c}\text { Song et } \\
\text { al. } \\
(2013) \\
\text { Ranking }\end{array}$} & \multirow{2}{*}{$\begin{array}{c}\text { Conventional } \\
\text { FMEA } \\
\text { Ranking }\end{array}$} & \multicolumn{2}{|c|}{ The TPOP } \\
\hline & & & & & $\mathbf{P S I}_{i}$ & Ranking \\
\hline$F M_{1}$ & 1 & 1 & 1 & 1 & 5.1385 & 1 \\
\hline$F M_{2}$ & 8 & 8 & 8 & 7 & 13.9679 & 8 \\
\hline$F M_{3}$ & 7 & 6 & 6 & 6 & 10.8311 & 6 \\
\hline$F M_{4}$ & 6 & 7 & 7 & 6 & 10.9073 & 7 \\
\hline$F M_{5}$ & 2 & 2 & 3 & 3 & 7.6829 & 2 \\
\hline$F M_{6}$ & 3 & 4 & 5 & 4 & 8.4953 & 5 \\
\hline$F M_{7}$ & 5 & 3 & 2 & 5 & 8.4849 & 4 \\
\hline$F M_{8}$ & 4 & 5 & 4 & 2 & 7.7591 & 3 \\
\hline
\end{tabular}

\section{CONCLUSION}

The problem investigated in this study was the confusion caused by different risk analysis and evaluation approaches and the different risk order rankings for the same failure modes. This is ranking inconsistency problem in the literature. To best of our knowledge, the solution of this problem in the field of occupational health and safety has not yet been studied so far. Due to this issue, occupational safety professionals are confused as to which risk priority order and preventive action plans to follow to eliminate the waste of resources and time. We proposed the use of the TPOP to overcome this problem. One case encountered in production systems was considered to demonstrate the usefulness of the proposed approach in solving real-life problems related to the occupational health and safety risk analysis and evaluation process. In our study, the final risk scores calculated using four different risk analysis and evaluation approaches proposed by different authors for eight failure modes defined for the nuclear reheating system in the study of Song et al. (2013) was used for case study. In case, the authors in the literature achieved different risk priority orders with different risk assessment and assessment approaches 
(see Table 2). These results did not overlap and were inconsistent. In our study, a single risk priority ranking order was obtained with the TPOP in practice, while 8 different risk priority levels were obtained for the 8 failure modes in case study (see Figure 3). In case, using TPOP, the risk order of failure types changed. A completely unexpected risk rank ranking was obtained for two of the eight risks, namely FM7 and FM8. According to the TPOP, these are among the first four risks. A useful risk order is critical for avoiding or minimizing risk (Hitam et al., 2004).

The main development, which arose from this study, was the suggestion to gather the advantages of different methods to obtain a single order by preventing the confusion stemming from different risk degree rankings obtained via different methods. It can be asserted that preventive actions can be planned in a fast, effective, and efficient manner if the most appropriate risk priority order is considered to improve occupational health and safety.

Although the TPOP has made a significant contribution to the inconsistent risk ranking problem by integrating the advantages of various approaches used for risk assessment methods, it has some limitations. Occupational health and safety professionals must apply different risk assessment methods before using the TPOP. It is not known how many methods should be studied with the condition of achieving superior success in the TPOP.

In future research, data fusion based approaches can be incorporated with the proposed approach for various approaches used for risk assessment in occupational health and safety. Additionally, fuzzy logic based the technique of precise order preference for risk assessment in the field of occupational health and safety assessment can be developed and applied to failure modes for ranking. 


\section{REFERENCES}

1. AlSabah, R., \& Refaat, O. 2019. Assessment of construction risks in public projects located in the state of Kuwait. Journal of Engineering Research, 7(3): 13-32.

2. Akdağ, C. H., Aybüke, U., \& Sezgin, U., 2016. Risk Analysis for Occupational Health and Safety and Risk Improvement: A Case Study in an Electric Electronic Company. Journal of Economics, Business and Managemen. 4(9): 515-522. https://doi.org/10.18178/joebm.2016.4.9.445.

3. Alencar, M. H., \& de Almeida, A. T., 2015. A multicriteria decision model for assessment of failure consequences in the RCM approach. Mathematical Problems in Engineering. 2015:1-10. https://doi.org/10.1155/2015/729865.

4. Antosz, K., \& Ratnayake, R. C., 2019. Spare parts' criticality assessment and prioritization for enhancing manufacturing systems' availability and reliability. Journal of Manufacturing Systems. 50: 212-225. https://doi.org/10.1016/j.jmsy.2019.01.003.

5. Aven, T., 2016. Risk assessment and risk management: Review of recent advances on their foundation, European Journal of Operational Research. 253: 1-13. https://doi.org/10.1016/j.ejor.2015.12.023.

6. Bairagi, B., Dey, B., Sarkar, B., \& Sanyal, S. K., 2015. A De Novo multi-approaches multi-criteria decision making technique with an application in performance evaluation of material handling device. Computers \& Industrial Engineering. 87: 267-282. https://doi.org/10.1016/j.cie.2015.05.015.

7. Bettayeb, B., Bassetto, S. J., \& Sahnoun, M., 2014. Quality control planning to prevent excessive scrap production. Journal of Manufacturing Systems. 33(3): 400-411. https://doi.org/10.1016/j.jmsy.2014.01.001.

8. Bian, J. P., Sun, X. Y., \& Yang, S. (2015). Risk assessment and working-out of maintenance strategy for power transformer based on cloud model. High Voltage Engineering, 41(10), 3342-3347.

9. Boye, T. E., \& Samuel, O. D. 2020. Computer-based method of design and modeling of transient flow in crude oil pipeline system. Journal of Engineering Research, 8(3): 219-229.

10. Chen, Y. 2016. Industrial information integration-A literature review 2006-2015. Journal of Industrial Information Integration, 2, 30-64. https://doi.org/10.1016/j.jii.2016.04.004. 
11. Dey, B., Bairagi, B., Sarkar, B., \& Sanyal, S. K. (2016). Multi objective performance analysis: A novel multi-criteria decision making approach for a supply chain. Computers \& Industrial Engineering, 94: 105-124. https://doi.org/10.1016/j.cie.2016.01.019.

12. Ekinci, E. B. M., \& Can, G. F. (2021). A novel aggregated multiple criteria decisionmaking approach to evaluate the physical workload of workers. Human Factors and Ergonomics in Manufacturing \& Service Industries. https://doi.org/10.1002/hfm.20924.

13. Emovon, I., \& Mgbemena, C. O. 2019. Enhancing the FMEA technique using a combination of Expectation interval, TAGUCHI, MOORA and Geometric mean methods. Journal of Engineering Research, 7(4): 238-260.

14. Fakhrzad, M. B., Firozpour, M. R., \& Hosseininasab, H. 2021. Comparing Supply Chain Risks Ranking in Multi-Attribute Decision Making Methods Using the Proposed Threedimensional Integration Mean Method. Asia-Pacific Journal of Operational Research, 2150006. https://doi.org/10.1142/S0217595921500068.

15. Friend, M. A., \& Kohn, J. P., 2007. Fundamentals of occupational safety and health. Rowman \& Littlefield. p.2.

16. Hitam, M. S., Gobee, S., \& Subari, K. (2004). A New Ranking Method For Fuzzy FMEA. In Applications and Science in Soft Computing .119-126). Springer, Berlin, Heidelberg. https://doi.org/10.1007/978-3-540-45240-9_17.

17. ISO 31000, 2018. Risk management - Guidelines. Available from: https://www.iso.org/standard/65694.html. Accessed15 January 2020.

18. Kutlu, A. C., \& Ekmekçioğlu, M., 2012. Fuzzy failure modes and effects analysis by using fuzzy TOPSIS-based fuzzy AHP. Expert Systems with Applications. 39(1): 61-67. https://doi.org/10.1016/j.eswa.2011.06.044.

19. Lv, Y., \& Liang, Y. (2014). Application of FMEA based on fuzzy multi-criteria decisionmaking for HVAC in a pharmaceutical plant. Journal of Chemical and Pharmaceutical Research, 6(6), 1116-1123. 
20. Manzini, M., \& Urgo, M., 2018. A risk based approach to support the supplying of components in a MTO assembly process. Journal of Manufacturing Systems. 46: 67-78. https://doi.org/10.1016/i.jmsy.2017.11.006.

21. OHS Risk Assessment Regulation,

2012. http://www.resmigazete.gov.tr/eskiler/2012/12/20121229.htm. Accessed 28 January 2020.

22. 89/391/EEC, 1989. Council Directive (EEC) 391/1989 of 12 June 1989 on the introduction of measures to encourage improvements in the safety and health of workers at work. OJ L183.

23. Ocampo, L., Masbad, J. G., Noel, V. M., \& Omega, R. S., 2016. Supply-side inoperability input-output model (SIIM) for risk analysis in manufacturing systems. Journal of Manufacturing Systems. 41: 76-85. https://doi.org/10.1016/j.jmsy.2016.07.005.

24. Pariyani, A., Seider, W. D., Oktem, U. G., \& Soroush, M., 2012. Dynamic risk analysis using alarm databases to improve process safety and product quality: Part I-Data compaction. AIChE Journal. 58(3): 812-825. https://doi.org/10.1002/aic.12643.

25. Saracino, A., Antonioni, G., Spadoni, G., Guglielmi, D., Dottori, E., Flamigni, L., ... \& Pacini, V., 2015. Quantitative assessment of occupational safety and health: Application of a general methodology to an Italian multi-utility company. Safety Science. 72: 75-82. https://doi.org/10.1016/j.ssci.2014.08.007.

26. Sharma, R. K., \& Sharma, P., 2010. System failure behavior and maintenance decision making using, RCA, FMEA and FM. J Qual Maint Eng. 16(1): 64-88. https://doi.org/10.1108/13552511011030336.

27. Sachdeva, A., Kumar, P., \& Kumar, D., 2009. Maintenance criticality analysis using TOPSIS. 2009 IEEE International Conference on Industrial Engineering and Engineering Management. IEEE. 199-203. https://doi.org/10.1109/IEEM.2009.5373388.

28. Segismundo, A., \& Augusto Cauchick Miguel, P., 2008. Failure mode and effects analysis (FMEA) in the context of risk management in new product development: A case study in an automotive company. International Journal of Quality \& Reliability Management. 25(9): 899-912. https://doi.org/10.1108/02656710810908061.

29. Song, W., Ming, X., Wu, Z., \& Zhu, B., 2013. Failure modes and effects analysis using integrated weight-based fuzzy TOPSIS. International Journal of Computer Integrated Manufacturing. 26(12): 1172-1186. https://doi.org/10.1080/0951192X.2013.785027.

30. Vaurio, J. K., 2011. Importance measures in risk-informed decision making: Ranking, optimisation and configuration control. Reliability Engineering \& System Safety. 96(11): 1426-1436. https://doi.org/10.1016/j.ress.2011.06.012. 
31. Zolfaghari, S., \& Mousavi, S. M. (2021). A new risk evaluation methodology based on FMEA, MULTIMOORA, TPOP, and interval-valued hesitant fuzzy linguistic sets with an application to healthcare industry, Kybernetes. 50(9): 2521-2547. https://doi.org/10.1108/K-03-2020-0184/full/html. 